\title{
Distant Encounters of a Third Kind: Problems of Generalism in the Teaching of Development Studies
}

\section{Raymond Apthorpe}

Because questions about relationships between ideas and interests are absolutely fundamental in social analysis they are so necessarily difficult to answer that $a$ solution is only marginally less suspect than the solution. Yet, since Plato at least, it is from speculations and discussions about how the human condition can be improved, ie from applied studies, that the most important insights into humankind's understanding of humankind have come. Thus far, general (rather than pure and unapplied) development studies have yielded few such new understandings. Why? What are the practical prospects of actually achieving a new, that is renewed, generalism in public policy studies?

The area of inquiry to be explored in this article is some aspects of the intellectual scope and nature of development studies since the end of World War II. It may prove difficult to separate this area sharply and completely from others, such as the morals and politics of our subject and the principal techniques of analysis on which it relies, but at any rate perhaps a difference in degree or emphasis can be maintained. Development studies have-again with exceptions-persisted over at least the last quarter of a century in being primarily third parties' doctrinal, visionary, distant encounters with what they construe as a world of a different, yes a third, kind. Interlarded though these may be with travel and adventure in distant lands they are, even so, seldom assisted-even technically-by those with historical insight and similar suitable preparation in the country or region concerned. This is very paradoxical, above all for studies which, precisely because they have been deemed to be about something 'other', surely require such insight in special measure.

So, what has happened? Much literature in development studies seeks just for 'models' to be learned and then replicated or transferred elsewhere. If there is anything at all to learn from this 'learn from models' literature, it is that 'the models' have come to take the place of what they were originally supposed only to represent. Such models are said merely to need replicating elsewhere; the literature is usually either silent altogether-or else extremely selective-about the political, historical, financial and other contexts in which the experience to be emulated occurred in the first place. Worse, as a rule, it does not consider the actual or potential options, or the costs of either. Seldom is the slightest inkling given of the setbacks that even success stories have probably faced at some stage. Image becomes mirage. The model is presented as if it were sufficiently descriptive as well as suitably prescriptive. Thus does one purpose or variety of development studies come to be confused with another, and as a result neither is well served.

\section{Interdisciplinarities}

At a conference once, a participant described herself as a 'specialist in general matters'. Is such a position tenable, and if so what does it amount to?

One of the main concerns in the learning and teaching of development studies is, by whatever methods, the assembling and interpreting of ideas and information for a policy-oriented study of action rather than a philosophy-oriented study of knowledge [Sinaceur 1977:571-9, Gusdorf 1977:580-600]. When this kind of intelligence work gets transferred from, as it were, the operations room to the universities, it may indeed be apt 'to get lost in discussions about the relations between disciplines, between the specialisations, and the temptations to discern the premises of a new synthesising, coordinating, unifying philisophy' [Sinaceur 1971]. The cosmology of educational institutions being dominantly discipline-structured, it is only to be expected that any attempt to transcend disciplines in them is likely to fall into the trap of trying to come up with a supra-discipline.

It is the idea that a specialist interdisciplinarity must be realised in an orthodox single disciplinary form that has helped lead to the institutionalisation in universities and institutes of, for example, 'development economics'. This relates to an idea that the disciplinary rigour and techniques in economics, which, for the most part have been developed outside growth studies, should be applied to development problems, and oriented towards economic policy and planning. The reasons why development economics has grown so strong, in outward results as well as in self-identity, could provide the basis for a separate discussion. It has in part been fostered as one way of making inter- 
disciplinarity practical and a single discipline less impracticable. The same could have been true in principle at least for 'development sociology' and 'development anthropology' if these too had proved to be growth industries in academia. They are not partly because even 'development economics' has come to stand as a warning.

At the onset of the 1970 s, much effort in sociology and social anthropology went into the production of something described as 'beyond the sociology of development'. This would present rather different issues for discussion if something substantial of the kind could really be brought forward for scrutiny, rather than it having remained, for the best reasons, more a sentiment unfilled than an achievement.

How, in practice, have interdisciplinary approaches actually been used? First, in most technocratic (and some reformist) policy circles, they seem to be commonly applied, in theory and in practice, to 'other' and not 'our own' (or even to 'other' in relation to 'our own') cultures, economies, societies. Only secondarily could they be said to have been applied to (say) the study of a particular topic, namely economic growth, since even the status quo in 'other cultures' is said not to be understandable ('to us') except in interdisciplinary terms. Certainly, many economic modernisation studies, and many in the dependency mode too, are about a perceived world which they suppose to be culturally completely, totally, other.

Disciplinaristic considerations about inderdisciplinarity prove to be secondary too-in studies abroad, at home, and in between. To take economics by way of example again, whilst for some of its practitioners [eg Thirlwall 1974] growth is properly a subject for study 'unadulterated' by the intrusions of other disciplines, for others [Loewe 1965:284] already some years ago it seemed as if the study of economic growth were to become the centre of a new Methodenstreit in which model-constructing theorists would vie with historically and sociologically minded empiricists'.

Everything has precedents. There is enlightenment and an Enlightenment. Advocacy of an 'enlightened interdisciplinary approach', as something other than simply 'multidisciplinarity by juxtaposition and accumulation on the heap of stones principle ... a monstrous epistemological Tower of Babel' [Gusdorf 1977], has been associated recently-precisely as it

\footnotetext{
I am grateful here to James Gould before the conference for reference to K. Simeonova, 1973, 'The interdisciplinary movement and the organisation of scientific research', Zagadnienia Naukoznawstwa (special issue on 'Problems of The Science of Science').
}

was in Europe in the eighteenth century-with Reason, Unity of Knowledge and yes Progress and Development and Unified Science. ${ }^{1}$ In this lies one, perhaps the chief, means for making interdisciplinary methods practical, namely the formalistic and neopositivist 'systems theory' version of the structural-functional vision in which all phenomena are quantified, or at any rate quantifiable.

This unification perspective could be called the academic method as in academic sociology, academic economics and academic political science and so on. There is a tendency perhaps for the view to prevail in academic interdisciplinarity that 'to ascertain the relative importance of economic and non-economic satisfaction ... is to ascertain the relative importance of measurable and non-measurable ones' [Scitovsky 1976], but this did not deter the rise of quantitative academic geography a decade or so ago, not to mention kinship algebra in anthropology, physics in politics, and so on, long before that.

A second variety of interdisciplinarity could be described less as unification than as partnership, usually of the rider and horse variety with, as a rule, economics in the saddle riding other-disciplines' beasts. This form saw a particularly intensive development in the early years of the Chicago journal Economic Development and Cultural Change, the most crucial characteristic of which, perhaps, is expressed succinctly in the very title itself.

A third variety could as well be called critical or radical. It would include the Marxist method which was critical of

the bourgeois academic economist [and bourgeois academic sociologists and political scientists etc] who attempted to draw a sharp line between static and dynamic analysis, hoping to transform the one into the other by injecting some 'dynamising' element into the static system. . . preferably expressible in equations, and relegate all that does not fit into the province of the sociologists. The academic sociologists make similar distinctions on a rather lower level of scientific interest, the historians on an even humbler one ... this is not Marx's way. The social relations of production (ie the social organisation in its broadest sense) and the material forces of production, to whose level they correspond, cannot be divorced ... 'Economic development' cannot be simplified down into 'economic growth'.

[Bottomore and Rubel 1978]

A fourth variety can be called dental. While in this variety of interdisciplinarity the participation of other disciplines may be needed (one could for exam- 
ple think of anthropology as optometry, geography as surgery, political science as ears, nose and throat medicine, and so on), it is to economics that the teeth in public policy are reserved. It differs from the horse and rider variety in not regarding partnership with other disciplines as absolutely essential but only as desirable. A fifth is bad (although this variety has no monopoly on badness). I am thinking here of those interdisciplinary teams which have been criticised or blamed, not for having no economist, sociologist, or whatever in them but only bad economists, sociologists, and so on, because their good cousins were more expensive and in any case preferred the more upright paths on which their professional careers depended. A sixth variety is wrong interdisciplinarity (which has no monopoly of wrongness), when either the wrong disciplines have been gathered for the task in hand or the right disciplines but the wrong specialisations inside them.

The fourth, fifth and sixth of these varieties resemble assemblages of disciplines (multidisciplinarity) more than new single disciplines of interdisciplinarity. But certainly these all contrast sharply with the single disciplinary approach, as in, for example, the orthodox opinion Loewe embraced in his earlier life (and rejected later) that "economic theory had to be a self-contained body of generalisation, independent of sociopolitical considerations and valid for all types of economic systems' (Loewe 1965), or various current textbook neo-classical positions and orientations and/or monetarist economic policy positions.

Some years ago, a past President of the Royal Economic Society observed that the several conspicuous advances in economics pertinent to development planning included '.. the refinement of the logic of resource allocation and decision making; the building of growth models; econometric analyses of systems of economic forces'. But he went on to say that, because the world's most pressing problems include

fostering growth in poor countries and improving the performance of the industrialised economies; adjusting the balance of payments; checking cost inflation while maintaining full employment; checking the adverse effects on the environment and the quality of life of industrialism; population growth and urbanism, [it would have been better for $]$. . the traditional boundary between the subject matters of economics and other social sciences [to be removed and for economists' studies in public policy to be] ... field-determined not discipline-determined.

[Phelps Brown, presidential address, Royal Economic Society, 1971]
I cannot at the moment think of a past President of a Royal Sociological or Social Anthropological Society being so forthright and so forthcoming in support of such a realistic, as well as generalist, position. This, however, may be for very understandable historical reasons: the somewhat separate professional development of applied anthropology for example, or post-independence developments in some African universities and institutes which have put anthropology in the former metropolitan countries on the defensive. But the story of sociology in the 'radical Africana' which emerged in the publishing world from the end of the $1960 \mathrm{~s}$, is rather different. At some risk of incest - the game that all family can play-the concept of 'a theory of practice' that the anthropologist Roger Bastide began to develop [Bastide 1973], and which potentially has a very wide scope indeed as a social method of development studies and development planning, could be turned first of all-but not here - to this sociological history.

Interdisciplinary efforts in universities have diversified into what in terms of their theoretical rationales could be called 'aspectual' and 'synthetic'. Commonly central to the aspectual perspective is a notion of rural (or other) development as something basically 'economic' but with 'social', 'cultural', 'physical' and other 'aspects' also of importance. Occasionally, development is conceived as being centrally something which is other than economic, merely having economic aspects. It is of course this pattern of thinking about aspectual elements that is most notably omnipresent in the 'modernisation' theme of the 'social obstacles to economic growth' literature.

Characteristic of the synthetic perspective is a view of social studies as being not discipline- but problemfocused. A primary postulate here is that problems in 'the real' world are very different from those in the 'academic'. If, with particular regard to rural development in other countries, synthetic interdisciplinary approaches to rural studies are less developed in agricultural colleges than elsewhere, this can be explained: they are best kept at a safe distance.

Aspectual interdisciplinary approaches in development studies founder principally in two ways. Either the individual disciplines in the mix 'talk past', or else 'talk against' each other. Talking past tends to be the trouble with alliances of say neo-classical economics with positive (also called neo-classical) sociology, where the economics brought to bear is a-social economics, and the sociology 'a-economic' (and a-political etc). Talking against each other, or simply not communicating at all, may be what usually happens when, say, neo-classical economies and critical sociology meet (or rather do not meet). The differ- 
ence is as much one of paradigms or conceptual schemes as of disciplines. Within even 'the same' discipline there are different schools of thought. The frontiers of knowledge in development studies would lie more at the limits of these than of the discipline [Lall 1976]. The integrity of the discipline may be no more than that of the school of thought. The world is, after all, fact as well as fiction.

The problems most commonly encountered by synthetic interdisciplinarity are the following. As seen 'from within' and 'from below',society is not as seamless as can appear 'from above'. This means that 'the' problem of, for example, 'poverty', is not singular but plural, a problem of poverties. Again, seen 'from below' and 'from within', problems tend often to be attributed to forces which in their origins and other ways are seen partly or even principally as coming 'from above' and 'from without'. Evaluations of policy and planning, where these are available at all, tend to be exceptionally difficult to use comparatively.

The varieties of interdisciplinarities in the academy have their parallels in the planning office. The physical planning which looks for physical solutions for physical problems, the economic planning which seeks economic solutions to problems seen as economic problems, and so on, is 'facet' planning. 'Integrated' means some kind of mix of physical plus economic plus other policy planning. Each instance of facet planning has its own characteristics to an extent. For example, physical planning tends, as a rule, to be concerned with stocks rather than flows because physical infrastructure is a stock of material goods in particular locations, with longer rather than shorter life spans. Economic planning tends to be more concerned with flows than stocks and tends often to be shorter term. Integrated planning means not simply the multiplicity or coordination of facet approaches but at least the simultaneous determination of the objectives, their trade-offs, and the joint use of policy instruments in all facet plans involved. ${ }^{2}$ It is, therefore, just like interdisciplinarity, a very rare phenomenon indeed in theory and in practice.

As with facet plans, so with single disciplines in schools and institutes of development studies. Each, to some extent, has its own character and delimited subjects and fields. At the same time, as also with facet plans, a number of concerns is common to them. Within the social sciences, as within the arts and humanities, any one 'subject' may intersect with any

\footnotetext{
2 This paragraph stems partly from discussions with Deryke Belshaw on regional planning at the School of Development Studies, University of East Anglia, some years ago.
}

other and between faculties there are linkages as well.

\section{Personalism}

Certainly many current attempts (my own included) to teach generalism in development studies are eclectic, opportunist. The choice of elements for a nondisciplinary understanding of even interdisciplinarity in development studies can be highly personal, given the shortage of the institutional, indeed institutionalised, apparatus of textbooks, dictionaries, audiovisuals and sets of past years' examination questions and the like that form the conventional stock-in-trade of all the more usual industries in academia. Why a more broadly based generalism has not been achieved-even in more or less specific regards-is not difficult to imagine. Some examples can be briefly introduced:

\section{i) 'Rural folk'}

First, and frequently most important of all, there is a background notion which comes to the very forefront of most interdisciplinary, and many disciplinary, concerns-namely that of 'rural folk'. It is common practice in many countries and theories-and not only development studies-to think of 'rural' and 'urban' as covering two 'different types of' society, with each having, as it were, its own political economy. This has meant that the teaching of 'rural development' in urban-situated and urban-staffed universities and institutes tends first of all to be about what is held to be a systematically other kind of society and culture altogether, in which the academics and policy makers themselves do not even move, let alone have their being. It tends to be mainly about wildly alternative strategies for growth and development to those which these authors and policy makers (ie we) could accept and act upon for their (ie our) own styles and modes of livelihood. Would 'we' for a moment contemplate taking the medicine we would recommend for others, even on those occasions when 'the ailment' is neither 'theirs' nor for that matter 'ours' but rather a common complaint and sometimes to some extent also of common genesis?

In such a context of social distance what has happened? The teaching-and the practice-of development studies has tended to become ripe simply for projections of the teachers' or policy makers' or administrators' own personal, professional, social or cultural hopes, fears, fantasies, ideologies and theories of value and what have you. Throughout social science history this has been so. For example, Marx on 'peasants', or on the 'Asian mode of production', is different from Marx on the period and the 
place which he had experienced and whose history he knew, namely industrial Europe. ${ }^{3}$ And so on.

It is precisely in this context of social and cultural distance and historical unreality that an interdisciplinary approach to development studies is the main a m tor some, and a toolish fad or fear for others. It is more in certain kinds of rural studies that this approach has been essayed to a characteristic degree. Turned on one's own face, the searchlight of interdisciplinary approaches is too uncomfortable because it is too blinding; turned on the faces of others, you can see them without, as it were, them seeing you. In certain kinds of urban development study also, interdisciplinary approaches have characteristically been applied to other cultural groups, such as "urban poverty groups'. Indeed, it was for these that the phrase 'the culture of poverty' was originally coined. ${ }^{4}$

The more remote and distant an object, the less direct knowledge one may have of it. In the absence of other information, one generalises. Where there are plants and animals, there are, as every farmer knows, insects too. So what are we to make of such accounts as those which appeared about rural development in China some years ago, in scientific as well as literary periodicals, that 'there are no files in China', ${ }^{5}$ or of such tour accounts as 'there are no slums, we didn't see any' or 'everyone looked well and healthy'.

It is of course about China that there are such reports. Philias flower, and phobias rage, if not on the basis of no knowledge at all, then of only very little. More, and the illusion is lost. China is 'a gigantic Rorschach card into which different people can project and find solutions to their homegrown discontents' [Berger 1974]. When I was teaching at the School of Development Studies at Norwich, both sinophilia and sinophobia in Third World rural development studies in Britain were as current as tanzaphilia and tanzaphobia, ${ }^{6}$ for similar reasons. It was believed, hoped, that in China and Tanzania the poverty and uncertainty of rural livelihoods had been successfully

\footnotetext{
3 The same would be true of many of the (single disciplinary) classics of, for example, sociology including those unrelated to the kind of change and development studies to which this article holds up a prism.

- See the work of Lee Rainwater and others discussed and developed in H. T. Gans, 1972, People and Plans: Essays on Urban Questions and Solutions (especially chapter 11 'Culture and class in the study of poverty: an approach to anti-poverty research'). I am grateful here (and elsewhere) to Henk van Roosmalen for his simple prism for the complex (or is it the other way round?).

5 At different times and of course from different perspectives 'no flies' were reported for both Republics of China: eg, G. S. Gale, 1955, 'No flies in China', Encrunter, 19, April, pp 20-31, and J. M. Brewster 'Traditional social st ructures as barriers to change' in C. Wharton (ed) 1969, Subsistence Agriculure and Economic Development.
}

transformed. At a safe distance, rural development in these two countries was contrasted with that in almost all the rest of the world. They were lessons in alternative futures even for rich countries suffering late monopoly capitalism. A remedy for ailments at home was available, only it was far away.

One problem with this position was, and to some extent still is, that because it was about something far away, one was not in a position to know very much about it except from a very limited range of sources, which were at least as often self-serving as not. Sinophilia and sinophobia supposed that what had become of 'rural folk' in China was known and understood sufficiently and was the way ahead to be recommended, or otherwise, elsewhere. Tanzaphilia - and at least to some extent tanzaphobiasupposed of 'rural folk' that what had been in Tanzania was self-evident and also pointed to the way ahead. In the one case planistration or poliplanistration was believed to have transformed, and in the other to have restored, rural society. Empirical and evaluative case studies were, for the most part, not available. Worse, they were not wanted. ${ }^{7}$

\section{ii) 'Ethnic folk'}

Other and similar forms of cultural idealism in public policy rationalisation and evaluation relate to institutionalism and ethnicism. Institutions seen as attitudes, sentiments, habits, customs, values, ethics and the like should be seen also as interests, politics, power conflicts, competitions, and thus, among other things, as matters of degree. And so they tended and continue to be in institutional economics in the USA, that is in the USA and on the USA at home. Abroad, however, the institutional and other components of other cultures are taken not only to be self-evidently other, outlandish, but also not to be matters of degree and shade-varying from one situation and set of circumstances to another-nor matters of interest, power and influence. Also these components are made to carry an extraordinarily large (and surely non-economic) share of the burden of explanation, as recourse to ordinary economic and other proofs has been ruled out. However legitimate this may be in certain circumstances, it is most certainly not an outcome of any close encounter with what is intended to be portrayed.

\footnotetext{
"On tanzaphilia see Colin Leys, Iransition, 1965. Note with reference to sinophilia/phobia debate, for example, such reactions to Simon Leys' work as Edward Friedman, 1978, 'Simon Leys Hates China: America loves Simon Leys', Bulletin of Concerned Asian Scholars, vol 10 no 3, pp 19-27. (Note also that Colin Leys and Simon Leys are different people.)

7 In lamenting the lack of precision that is the necessary price of views from afar, it is true too of course that perspective can be gained only at a distance.
} 
It is by no means only academic economics that is to blame. The actual practice of anthropology as a professional academic discipline, and more publicly, has gone hand in hand with the intellectual creation, at least justification, of a Third World. Anthropological and other endeavours to comprehend the diversity of humankind originally took to Africa and India-rather than finding there-certain social notions such as 'tribe' and 'caste'. Neither is this a one-way approach:'European' challenges naturally called forth 'African', 'Asian' and other responses. Of the nature and scope of the mental export, as it were of a Third World to a Third World, there is much to be learned from a sharp criticism of some recent approaches in international relations and policies towards and in the 'Middle East' (West Asia)':

Thequestions to be asked are not military or political or tactical in the narrow sense. You must ask your expert A rabists . . to tell you why they misin formed you about Arab traditions and 'the Arab mind', why they preferred to prove an innate Arab hostility and passivity by scandalous distortions of history all the people feel and have felt when they are bullied, why they are demoted to second class citizens on their own land, where they are treated as bad natives.

[Said 1974]

A few years later, having observed that gross ignorance persisted, as it will whenever fear of the different gets translated into attempts at domination, the same writer went on to explain:

Academic experts decred that in Islam everything is Islamic which amounted to the edifying notions that there was such a thing as the 'Islamic mind', that to understand the politics of Algeria one had best consult the Koran, that they (the Muslims) had no understanding of democracy, only of repression and mediaeval obscurantisms. Conversely it was ageed that so long as repression was in the US interest it was not Islamic but a form of modernisation. The worse misjudgements followed ... Suddenly it appeared that Islam was back when Ayatollah Khomeini, who derives from a long tradition of opposition to outrageous monarchy, stood on his national, religious and political legitimacy as an Islamic righteous man. But in Iran and elsewhere, Islam had not simply 'returned'; it has always been there not as an abstraction or a worry but as part of a way people believe, give thanks, have courage, and so on ... Muslims live in history and in our common world, not simply in the Islamic context.

[Said 1979]
The Guardian newspaper in a leading article the other day was speaking of 'the worst in the Iranian character' and of 'Iranians [being] all of a piece'. This, precisely as Fred Halliday said in a letter (10 November 1979) to that newspaper, is only

to resort to the kind of haughty racist generalisation that has mercifully now been driven out of public discourse when applied to such victims of oppression as Blacks, Jews and the Irish. . . The irony is that in positing an essentially 'extremist' Iranian character against an implicitly reasonable Guardian-reading westerner, you merely reverse the simplistic outlook of the ... pure Islamic East and [the] corrupt infidel West.

This kind of pattern and process of misunderstanding has a number of predictable and easily distinguished features. The habits of mind that in the West distort our views of the East are often basically the same as those which have warped our views of the West as, for example, when one analyses by opposites, like good versus bad, spiritual versus material, and so on. The terms in which the uniqueness of the East is described originally referred to perceived contrasts in the West. It follows that such conceptions and perceptions may tell us more about the West and projections of $i t s$ hopes and fears than about the East. It is only to be expected,therefore, that for example '... the Eastern Despot is essentially a European concept and [that] the story of its fortunes belongs properly to the history of European thought rather than to the history of Asia, [Steadman 1969].

When other cultures are seen also as other periods, for example in a succession or sequence of stages of history - any or each of which may at different times be found in a different place-new realms of difficulty for public policy analysis appear alongside the old. Whenever concepts such as 'feudal', 'precapitalist' and indeed 'capitalist' which normally are used in evolutionary and similar ways, are used outside theories of evolution, for evaluation, even the 'mode of production' can hardly be domesticated into a productive 'mode of thought'.

Stereotypically the-anthropologist is supposed to be a romantic. Anthropology is based upon and prizes a much more diffuse (less role segmented) involvement in "field work" [than sociology] . . both in the intensity of involvement that it permits and in the diversity of personal attributes that it requires' [Gouldner 1975]. It does not exactly fit this image if the anthropologist comes from the perils and pleasures of the field with a message such as, well, you see, while 'certainly a European or American would be entitled to feel that the Islamic multitudes are underde- 
veloped, yet ... underdeveloped is a relative cultural and economic judgement and not mainly 'Islamic', in nature [Said 1979].

Non-cultural-idealist positions are precisely what an anthropologist is conventionally expected to avoid because in effect they act to devalue his or her travels into distant and exotic lands. Encounters of a third kind have, for anthropologists, understandably and given the structure of the rest of academia, been professionalised. Substantivism in social science has a special association with, and value for eg some schools of economic anthropology ${ }^{8}$ while for others [Semenov 1975: 207-13] it 'misses the point' altogether.

\section{iii) 'Summit folk'}

And now another perceived, and perceiving, species, 'summit folk'. Different fields of development studies have their own forms of learned ignorance. One of these, in population studies, surfaced in the speech read by the President of the World Bank in April 1977 in which high population growth was explained only with reference to ' . . religious, social and political reasons', whilst economic and ecological reasons received no mention. This 'view from above' can be regarded as a particular variety of summitry (which is by no means confined just to population studies). The effect of it-if any-may well be actually to help create a pro-natalism, which is or becomes religiously or socially inspired, where it did not exist before (or to reinforce a pro-natalism which did already exist). Politicians and, of course, the rural bulk of the population at large-in poor countries at any rate-are perfectly well aware of economic reasons ${ }^{9}$ why some farm families are planned to be large. The McNamara statement, by dwelling on 'religion' and so on, has the probably unintended effect of making the 'non-economic' appear as not non-, but anti-, or dis-, economic.

In demogenics, as in other branches of our subject, the researcher and teacher as well as the public spokesman and policy maker are apt to lose touch with economic, and ecological, realities. One way of doing this follows from simply misinterpreting or misrepresenting an economic factor by calling it a social factor. Another follows from supposing that

- See, for instance, M.Sahlins, 1974, Stone Age Economics. For an introduction to a discussion 'The substantivist-formalist controversy', see Anne Sharman-Bader, 1975, Department of Sociology, University of East Anglia, mimeo.

- See Raymond Apthorpe, 1974, 'Population, public policy and social development', Philippine Planning Journal Vl, 1 October, pp 1-12 as well as, of course, the more substantial research by Mamdani, Ben White and others noticed by Mavin Harris, in Cultural Materialism (1979). substantively economic factors necessarily divide into different orders of importance, corresponding with what are seen as different types or orders of society, or culture, from one's own, and then, conveniently, putting the economics of these other societies right out of analytical court. A third-especially in population studies-is simply to brand a whole complex of issues as being of interest to 'Marxists' only.

With this confusing of certain kinds of 'economic' with certain kinds of 'social', 'religious', 'political' and other factors, it is only natural that other cultures and societies should be found to be so categorically different as to be inordinately difficult to analyse. So labels are used instead-bad ones like 'superstition', good ones like 'how interesting'. The standpoint of generalism in development studies does not require or imply that there are no differences at all between one culture and society or another. That would be culturally and socially, let alone intellectually, absurd. It is rather that cultures and societies are not normally, as it were, completely other, completely different, as culturally idealist positions tend to suppose. A norm, a sanction, a validation or a legitimation, is not necessarily at the same time also a description or an evaluation of actual behaviour in any society. If it were, there would probably have been no need in social studies for a concept of norm, in the first place.

The speech just mentioned suggested that the allocation of public services should be denied to parents with more children than some specified norm. Even to contemplate such a policy without taking into account economic realities of both wants and needs for more children in, for instance, certain kinds of agricultural situation, is not simply to make a false analysis: it is to make no analysis at all.

Of course 'social' and 'economic' can be construed, either very differently or very similarly, in any number of ways and certainly not only those just touched on here. If 'the economic' can somehow be included in 'the social', the opposite is also the case, and one view of 'Marx's system' was that its

closed spiral linkage of events [was] due to the absorption of the social into the economic process [with] the reciprocal relations [being understood as] much more comprehensive, [and with] the institutional framework ... no longer seen as a constant but as subject to a predictable process of transformation. . . Once capitalist evolution is set on its fateful course nothing can remain invariant. In methodological terms no independent variables are left; a cyclodynamic feedback mechanism has swallowed up the 'knowns' as well as the 'unknowns' of the problem.

[Hobsbawm 1964] 
Neglect, or encapsulation, of a variety of materialist notions in a variety of ideationist ones is, seen 'from below', often a general feature of views 'from above'. Hierarchies may appear to be founded on different principles and premises according to whether one is taking a top downwards, or a bottom upwards, view of, or in, them. Cultural idealism is very much associated with top downwards explanations and evaluations. Role theory in social structural and other analysis is but one example of this. It is interesting historically that in Vilfredo Pareto's system, 'role' was primarily used in the sense of a professional role such as that of a lawyer, namely, with reference to a position 'at a certain altitude' in society [Pareto 1935: chapter 12]. To use role theory as a means of conceptualising and understanding an entire society of roles and positions and statuses and persons, but regardless of their different levels in society, could result in simply denying existence to these levels. This would be not flat earth but flat society theory.

We are all 'ethnic folk' in a way, all 'summit folk' at some level. Some of us rural too. The purposes for which cultural idealism is unsuitable are not the only ones in development studies. Indeed, inspirational endorsements and essentialist re-endorsements of thought and action (as when a secretary might say he 'couldn't be accused of being lazy because he was a Protestant', or a student that she 'occupied the embassy in the name of Islam, not any particular political party' have instrumental as well as other value [Apthorpe and Gasper 1979].

\section{Where Do We Go from Here?}

Where do we go from here? If remedies lie in the looking for them, as a student of S. F. Nadel's Social Anthropology was brought up to say, then, where should we look?

There is, I believe, something to learn especially for the teaching of development studies, from the position in literary criticism that to understand Ben Jonson and enjoy him 'does not so much require the power of putting ourselves into seventeenth century London as it requires the power of setting Jonson in our London' [Eliot 1919, 1941]. The point is that to do this, one will have, not least, to understand 'our London' as well. Such less abstract approaches would not only unpack or unload these categories and think, say, of 'Whitehall' not 'Westminster' (just to keep within summit London); of say 'neo-classical' rather than 'western' economics or sociology; of at least say 'India' or 'China' rather than 'Asia'; 'Nigeria' or 'Uganda' rather than 'Africa', and so on. Such approaches would identify the authorship of these more limited accounts or impressions and then, again like literary criticism, ask about the relationships and the interrelations between subject and author, author and subject, and the meanings and purposes of these.

The teaching of development studies should also always distinguish between such purposes and varieties of our concerns as description, explanation, prescription, prediction, diagnosis and evaluation before going on to see whether any links can, or cannot be made, between them.

The difficulties for an interdiscipline, or a new single discipline, or a non-discipline, of development studies, are indeed very similar to those confronting a general theory of planning if

the kinds of problems that planners deal withsocietal problems-are inherently different from the problems that scientists and perhaps some classes of engineers deal with. Planning problems are inherently wicked... there is no definitive formulation of a wicked problem ... wicked problems have no stopping rule... solutions to wicked problems are not true or false but good or bad ... there is no immediate and no ultimate test of a solution to a wicked problem ... every solution to a wicked problem is a one shot operation; because there is no opportunity to learn by trial and error, every attempt counts significantly... every wicked problem can be considered to be a symptom of another problem.

[Rittell and Webber 1973: 155-69] ${ }^{10}$

A common, a scope and nature, a principles or a generalist course is one, but obviously only one, of the elements that go to make up a development studies curriculum. In the development studies curricula familiar in Western Europe, Africa or Asia, both disciplinary and interdisciplinary approaches appear to invest more in their 'specialist' rather than 'generalist' components. Their generalism may be either disciplinary or interdisciplinary, or both, in its effects and outcomes. But in their concerns with public policy problems and the histories of thinking and theorising about them, 'generalist' courses of study have to transcend their particularist sources of all kinds and thus become nondisciplinary in intent-until the generalist study of change and development is itself seen as a new single (not supra), discipline. Whereupon the whole process of establishing and clarifying generalism will need to start again.

How different sorts of problems are defined will depend in part, of course, on what sorts of solutions

\footnotetext{
10 The debate that followed the publication of this essay in the same journal, joined by J. F. Reynolds and Milton Marney. and A. J. Baum (eg see vol 6 no 1), while refuting some overstatement, is itself overstated, as Desmond Gasper remarks (in litt).
} 
to them could, and should, be sought. ${ }^{11}$ Problems for policy studies are 'wicked' if the solutions envisaged and sought for them are 'wicked' too. This may be not for any scapegoating reason but, for example, because of the theories of planning which imply that the rules of the game should be subject to review and change even while the game is being played. If the problems for development studies are nondisciplinary in the first (or last) place, then obviously a specifically disciplinary or interdisciplinary search for them gets off to a bad start. If, in addition, this start is also historically and culturally 'external' it stands to reason that the approach is at an even greater disadvantage.

Development studies are, in short, doubly distanced. First, there is the general character of the social sciences which has itself been described as 'founded on what Jacques Berque has termed the dialectic of the Same and the Other, the alternating of cumulative process of identification and "distancing". . . [Sachs 1976: 75]. ${ }^{12}$ Regardless of the parts of the globe and the periods of time at issue, there is much reliance, in (perhaps all) science, on other-ification (also known as object-ification). Second, as the instances ${ }^{13}$ 'rural folk', 'ethnic folk' and 'summit folk' in this article. have shown, development studies social science has come to be almost exclusively about an objectively and subjectively perceived entirely Other World. The discovery of the Third World does indeed mark a caesura in the history of our generation [Sachs 1976: $x i, f n$ 3]. But isn't it a matter more of invention than discovery?

\section{References}

Apthorpe, Raymond, 1974, 'Population, public policy and social development', Philippine Planning Journal, vol 6 no 1, October

—and Desmond Gasper, 1979, Public policy metaevaluation', ISS Occasional Papers no 75, The Hague

Bastide, Roger, 1973, Applied Anthropology, Croom Helm, London

1 This is not considered adequately in the debate relating to Rittel and Webber's position noted above.

12 This refers to Berque [1970]. I am grateful to Bernard Schaffer for a similar observation.

${ }^{13}$ These are only three among many instances that come to mind. They are of two kinds because the perceived also perceives, so all these kinds of conceptions and perceptions are necessarily relativist.
Berger, P. L., 1976, Pyramids of Sacrifice: Political Ethics and Social Change, John Lane, London

Berque, J., 1970, 'L'orient et l'avenement de la valeur monde', Esprit, September

Bottomore, R. B. and M. Rubel (eds), 1978 edition, Karl Marx: Selected Writings in Sociology and Social Philosophy, Penguin Books

Eliot, T. S., 1919, Ben Jonson

-1941, Points of View, Faber, London

Gouldner, A. W., 1975, For Sociology: Renewal and Critique in Society Today, Penguin Books

Gusdorf, Georges, 1977, 'Past, present and future in interdisciplinary research', UNESCO International Social Science Journal, vol 29 no 4

Hobshawm, E. J. (ed), 1964, Karl Marx: Precapitalist Economic Transformation, Lawrence

Lall, S., 1976, 'Conflicts of welfare: welfare economics and developing countries', World Development, vol 4 no 3, March

Loewe, A., 1965, On Economic Knowledge, Knopf

Pareto, Vilfredo, 1935, The Mind and Society, vol IV, (translated by A. Bongiorno and A. Livingstone), Jonathan Cape, London

Rittel, H. W. J. and M. M. Webber, 1973, 'Dilemmas of a general theory of planning', Policy Sciences 4

Sachs, Ignacy, 1976, The Discovery of the Third World, MIT Press, Cambridge Mass

Said, E., 1974, Newsweek, 2 December

-1979, Time, 16 April

Scitovsky, Tibor, 1976, The Joyless Economy, Oxford University Press

Semenov, Y. I., 1975, 'Marxism and primitive society', Philosophy of Social Science, vol 5, pp 207-13

Sinaceur, Mohammet Allal 1977, 'What is interdisciplinarity?', UNESCO International Social Science Journal, vol 29 no 4

Thirlwall, A. P., 1974, Growth and Development with Special Reference to Developing Countries, Macmillan 